\title{
Possibilidade da transmissão congênita de Toxoplasma gondii em ovinos através de seguimento sorológico no município de Rosário do Sul, RS, Brasil
}

\author{
Possibility of Toxoplasma gondii congenital transmission in sheeps by serological follow-up in \\ Rosario do Sul county, RS, Brazil
}

\author{
Karin Lucianne Monti de Vasconcellos Silva' ${ }^{1}$ Mário Luiz de la Rue ${ }^{2}$
}

\section{RESUMO}

No presente trabalho, descrevem-se os resultados da detecção de anticorpos anti-T. gondii (IgG e IgM) em amostras seqüenciais de soro de cordeiros recém-nascidos e de suas mães, sem aparentes sinais clínicos da infecção. Os anticorpos IgG foram quantificados pelos testes de imunofluorescência indireta (IFI) e hemaglutinação indireta (HAI). Os anticorpos IgM foram detectados pelo método de hemaglutinação indireta 2-mercaptoetanol (HAI / 2-ME), utilizando "kits" comerciais. Foram considerados reagentes títulos maiores ou iguais a 16, na hemaglutinação, e 20 na imunofluorescência. Coletou-se soro de 247 ovelhas e cordeiros $e$, após três meses, somente dos cordeiros $(n=120)$. Do total de animais, 175 eram de uma propriedade e 72, de outra propriedade, ambas localizadas na zona rural do município de Rosário do Sul, RS, Brasil. Em 22 cordeiros (18,3\%), do total analisado, que apresentaram títulos na primeira coleta, houve decréscimo ou negativação da resposta imunológica indicando transferência passiva de anticorpos. Apenas quatro animais (3,3\%), cujas mães indicavam infecção recente, apresentaram títulos crescentes de $\operatorname{Ig} G$ da primeira para a segunda coleta, sugerindo a possibilidade de transmissão congênita de T. gondii.

Palavras-chave: Toxoplasma gondii, ovelhas, transmissão congênita, IgG, IgM, Rosário do Sul.

\section{ABSTRACT}

The present study describes the detection of anti-T. gondii antibodies (IgG and IgM) in sequential serum samples from lambs and their mothers, without clinical signs. IgG antibodies were quantified by indirect imunofluorescence (IFI) and indirect hemaglutination (HAI). IgM was detected using HAI 2- mercaptoethanol, by commercial kits. Titers higher than 16 for hemaglutination and 20 for imunofluorescence were considered positive. 247 sera samples were analysed and,

\begin{abstract}
after a three months interval, more 120 sera samples from their lambs were studied. There were 175 sheeps in one property and 72 sheeps in the other, both situated in the rural area of Rosário do Sul county, RS, Brazil. Through serological analysis were detected 22 lambs (18.3\%) who showed titers in the first test, which declined and also negativated the imunological response in the second test, indicating antibodies passive transference.Only at four lambs (3.3\%), whose mothers presented early infection, IgG titers increased from first to second test, suggesting possible congenital transmission of $\mathbf{T}$. gondii.
\end{abstract}

Key words: Toxoplasma gondii, sheep, congenital transmission, IgG, IgM, Rosário do Sul.

\section{INTRODUÇÃO}

O Toxoplasma gondii (Nicolle \& Manceaux, 1909), agente da toxoplasmose, infecta um expressivo número de mamíferos, incluindo o homem. Ele parasita seu hospedeiro sem manifestar sinais clínicos; porém, é capaz de causar uma doença grave, principalmente quando ocorre a transmissão congênita (DUBEY, 1993).

Os felídeos são os principais responsáveis pela disseminação desta zoonose, pois eliminam oocistos infectantes em suas fezes. O parasita também é transmitido pelo consumo de tecidos animais contendo seus cistos (BUXTON, 1991; DUBEY, 1994). A transmissão congênita ou transplacentária, porém, é freqüentemente a mais grave. Esta forma de propagação ocorre normalmente na fase aguda da doença, ou, no caso de reagudização da doença crônica, durante a gravidez (KAWAZOE, 2005).

${ }^{1}$ Programa de Pós-graduação em Medicina Veterinária Preventiva, Universidade Federal de Santa Maria (UFSM), Santa Maria, RS, Brasil.

${ }^{2}$ Departamento de Microbiologia e Parasitologia, Centro de Ciências da Saúde, UFSM, Camobi, 97105-900, Santa Maria, RS, Brasil. E-mail: delarue@smail.ufsm.br. Autor para correspondência. 
A transmissão congênita deste parasita é relativamente comum em pequenos ruminantes e, na espécie ovina, pode levar a perdas na produção, além de servir de fonte de infecção ao homem, quando este se alimenta da carne mal cozida. A doença clínica ocorre na forma de problemas perinatais como abortos, natimortos e cordeiros recém nascidos fracos (URQUHART et al., 1998). Esta zoonose foi relatada pela primeira vez, em ovinos, em 1942, nos Estados Unidos da América (SPOSITO FILHA et al., 1992). Posteriormente, foi reconhecida como causa de esterilidade, natimortos e abortos em ovinos em vários países, sendo mais freqüente em rebanhos estabelecidos em terras baixas e úmidas, onde os oocistos resistem por maior período de tempo (BEVERLEY et al., 1971; DUBEY \& KIRKBRIDE, 1989).

A taxa de aborto causada por T.gondii em ovinos varia, segundo diversos autores, entre 0,7 e $4 \%$ (BLEWETT \& TREES, 1987; FREYRE et al, 1997), podendo a incidência, ao correr dos anos, aumentar de 12 a 17\% (BLEWETT \& WATSON, 1984; MARTÍN,1984; DUBEY \& KIRKBRIDE, 1990). Embora seja clássico o conhecimento da freqüência da infecção por T. gondii em ovinos e suas conseqüências patológicas no feto, a informação disponível para a América Latina é discreta (FREYRE \& FALCON, 1990).

A ocorrência de aborto depende da fase de prenhez em que a ovelha se infectou e muitas vezes passa despercebida; ou, por outro lado, pode ocorrer a reabsorção fetal, se a infecção ocorreu na primeira etapa da gestação, e a ovelha passa a ser considerada estéril (DACOSTA, 1980).

DUBEY et al., (1987b) sugerem que a pesquisa de anticorpos anti-T. gondii no soro de recémnascidos seja um método apropriado para detectar a toxoplasmose congênita em rebanhos ovinos desde que não haja placentite induzida por endotoxinas, o que levaria à passagem de anticorpos maternos pela placenta.

A pesquisa de anticorpos IgG e IgM pelo teste de hemaglutinação indireta (HAI), de hemaglutinação indireta 2-mercaptoetanol (HAI/2 ME) e a pesquisa de IgG pelo método de imunofluorescência indireta (IFI), em análises seqüenciais de amostras de soros, têm sido utilizadas para o diagnóstico de toxoplasmose congênita. A produção da imunoglobulina $\mathrm{M}$ aparece inicialmente, caracterizando a fase aguda da enfermidade, seguida de imunoglobulina G, que aparece mais tardiamente. Os títulos de IgG se mantêm constantes ou ascendentes se houver a infecção, decrescendo ou até desaparecendo em prazo de poucos meses, no caso da transmissão passiva de anticorpos pelo colostro (DUBEY et al., 1987a).
A comparação com o soro de cordeiros três meses após o nascimento pode permitir avaliar a possível transmissão transplacentária de $\boldsymbol{T}$. gondii em ovelhas naturalmente infectadas em área do estado do Rio Grande do Sul, onde a ovinocultura é expressiva. Baseado nisto, a proposta do presente trabalho foi a detecção de anticorpos contra T. gondii no soro de ovelhas e o seguimento dos cordeiros recém-nascidos.

\section{MATERIAL E MÉTODOS}

Fizeram parte do estudo animais de duas propriedades rurais do município de Rosário do Sul, Rio Grande do Sul, sendo uma distante $98 \mathrm{~km}$ da zona urbana e a outra $12 \mathrm{~km}$ do centro da cidade, sendo que ambas possuíam gatos. O critério de escolha das propriedades foi devido a possuírem rebanhos com controle de nascimento e história prévia de abortos e natimortos. O município de Rosário do Sul localiza-se na região Centro-Oeste do Estado, com uma população urbana de 35.890 habitantes, e 5.135 moradores na zona rural. A localização da sede municipal é: $30^{\circ} 14^{\prime} 60^{\prime \prime}$ S e $54^{\circ} 55^{\prime} 55^{\prime}$ ' W e a altitude é de 125 metros sobre o nível do mar (2001- Informe verbal ${ }^{\mathrm{b}}$ ). Seu rebanho ovino é de 136.021 animais (2001-Informe verbal ${ }^{\mathrm{a}}$ ) e sua economia está voltada para a produção agropecuária. Os animais que fizeram parte do estudo foram 175 ovinos, identificados por tatuagem, numa propriedade (1999), e 72 animais, também identificados, em outra propriedade (2000).

Das primeiras 175 amostras de sangue, 87 eram de ovelhas e 88 de cordeiros lactentes (1 mãe teve gêmeos), tem sido coletadas no mês de agosto de 1999. Em novembro do mesmo ano, coletaram-se 85 novas amostras de sangue dos mesmos cordeiros (três cordeiros morreram). As outras 72 amostras (segunda propriedade) foram coletadas em agosto e mais 36 em novembro de 2000. A colheita foi realizada por punção venosa e o sangue centrifugado a 3000xg durante 15 minutos e os soros armazenados a $-20^{\circ} \mathrm{C}$.

Antes das análises, o material foi inativado a $56^{\circ} \mathrm{C}$ por 30 minutos e submetido ao teste de hemaglutinação indireta (HAI) e 2 mercapto-etanol (HAI/2 ME) para detecção de anticorpos anti-T. gondii, respectivamente das classes IgG e IgM. Concomitantemente, os soros foram submetidos à reação de imunofluorescência indireta (IFI) para detecção de anticorpos anti-T. gondii, da classe IgG, conforme técnica descrita por CAMARGO et al. (1991). Para realização dos exames de HAI, HAI/2 ME foram empregados "kits" de uso comercial (Biolab-Mérieux SAC), conservados entre $2-8^{\circ} \mathrm{C}$, com todos os reativos e seguindo-se as indicações do fabricante. 
Inicialmente as amostras do soro foram diluídas a 1/16 e as reagentes foram submetidas a diluições seriadas, múltiplas de dois, para realização de técnica de hemoaglutinação, como triagem. Realizaram-se as leituras, considerando como título aquele onde ainda havia aglutinação de hemáceas, observado ao microscópio ótico com aumento de 100X.

Os testes de IFI foram realizados para detecção de anticorpos IgG, utilizando-se suspensão liofilizada de T. gondii obtida de camundongo (BiolabMeriéux S.A.c), fixada em lâmina de imunofluorescência. Para a diluição dos soros do conjugado anti-IgG (globulina anti-IgG ovina marcada com isotiocianato de fluoresceína- $\left(\right.$ Sigmad $\left.^{\mathrm{d}}\right)$ e para a lavagem das lâminas foi usado PBS (solução salina tamponada de pH 7,2). O conjugado anti-IgG foi diluído para a obtenção do título ideal, sendo empregada a diluição de 1:40. As amostras positivas na diluição inicial de 1:20 foram novamente diluídas até a obtenção de maior diluição que ainda fornecesse fluorescência verde-maçã intensa (BERTSCHINGER, 1980).

\section{RESULTADOS E DISCUSSÃO}

A possibilidade de transmissão congênita de T.gondii a campo foi analisada neste experimento, de modo a avaliar as condições naturais de infecção e transmissão. Tem-se consciência da dificuldade de padronizar as inúmeras variáveis existentes, bem como da perda devida ao aborto espontâneo que ocorre no campo. Além disso, há a dificuldade de fazer o acompanhamento de cada ovelha prenhe durante as 24 horas do dia, na época da parição, em propriedades com criação extensiva. Por esse motivo, optou-se por uma análise sorológica das ovelhas e de sua prole, o que possibilitaria o relacionamento com a transmissão congênita do parasita.

Na primeira fase do experimento, das 87 ovelhas testadas, 39 (44,8\%) foram sorologicamente IgG-reagentes a antígenos de T. gondii pela imunofluorescência e 17 (19,5\%) pela HAI (Tabela 1). Das reagentes, 10 ovelhas apresentaram títulos iguais ou superiores a 128 pela HAI e 15 apresentaram títulos iguais ou superiores a 160 na IFI (Tabela 2).

Dentre as ovelhas que apresentaram títulos, três ( $\mathrm{n}^{\circ} 1, \mathrm{n}^{\circ} \mathrm{4}$ e $\mathrm{n}{ }^{\circ}$ ) $)$ foram IgM e IgG reagentes, simultaneamente; porém, somente duas delas (1 e 5) tiveram seus cordeiros com títulos crescentes da primeira (1: 2.048 e 5: 32.768) para a segunda (1: $8.192 \mathrm{e}$ 5: 131.072) coleta na HAI, resultados esses que se confirmaram na IFI (Tabela 2). A ovelha n. ${ }^{\circ} 9$ foi reagente pela IFI e negativa pela HAI, e seu cordeiro teve títulos crescentes da primeira para segunda coleta pela IFI, enquanto que pela $\mathrm{HAI}$, foi reagente apenas na segunda coleta. O mesmo ocorreu com a ovelha 12, apesar de o seu cordeiro ter sido reagente pela IFI somente na primeira coleta. Para CAMARGO (1996), esta discrepância de títulos entre as reações é um bom marcador de infecção recente, pois, no teste de HAI, anticorpos IgG de baixa avidez, como ocorrem no início da infecção, têm pouco poder aglutinante. Disso resultam títulos baixos, embora elevados nos testes de IFI, os quais não dependem da ação aglutinante dos anticorpos .

Na segunda parte do trabalho, das 36 ovelhas analisadas (Tabela 3), nove (25\%) foram reagentes pela IFI, oito (22,2\%) pela HAI e cinco (13,9\%) foram IgM reagentes. Dos cordeiros, nove (25\%) foram reagentes pela IFI e cinco (13,9\%) pela HAI. Apenas uma ovelha (4) teve seu cordeiro com títulos crescentes em relação à primeira (4: 512-HAI) (4: 2560-IFI) e à

Tabela 1 - Sorologia de ovelhas e de seus respectivos cordeiros para pesquisa de anticorpos anti-Toxoplasma gondii no município de Rosário do Sul (RS) por imunofluorescência indireta (IFI), hemaglutinação indireta (HAI),e hemaglutinação indireta 2mercaptoetanol (HAI 2-ME) nos anos de 1999 e 2000.

\begin{tabular}{|c|c|c|c|c|c|c|c|c|c|c|c|c|c|c|c|}
\hline \multicolumn{8}{|c|}{ ovelhas } & \multicolumn{8}{|c|}{ cordeiros } \\
\hline & \multirow{2}{*}{\multicolumn{2}{|c|}{ IFI }} & & & & \multicolumn{5}{|c|}{$1^{\text {a }}$ coleta } & \multicolumn{5}{|c|}{$2^{\mathrm{a}}$ coleta } \\
\hline & & & \multicolumn{3}{|c|}{ HAI/ HAI 2- ME } & \multicolumn{2}{|c|}{ IFI } & \multicolumn{3}{|c|}{ HAI/ HAI 2-ME } & \multicolumn{2}{|c|}{ IFI } & \multicolumn{3}{|c|}{ HAI/ HAI 2- ME } \\
\hline ANO & $\mathrm{n}$ & $\%$ & $\mathrm{n}$ & $\%$ & $\mathrm{t}$ & $\mathrm{n}$ & $\% 0$ & $\mathrm{n}$ & $\%$ & $\mathrm{t}$ & $\mathrm{n}$ & $\%$ & $\mathrm{n}$ & $\%$ & $\mathrm{t}$ \\
\hline 1999 & 39 & 44,82 & 17 & 19,54 & 87 & 17 & 19,31 & 5 & 5,68 & 88 & 8 & 9,41 & 3 & 3,52 & 85 \\
\hline 2000 & 9 & 25,00 & 8 & 22,22 & 36 & 9 & 25,0 & 5 & $\begin{array}{l}13,8 \\
8\end{array}$ & 36 & 8 & $\begin{array}{l}22,8 \\
5\end{array}$ & 1 & 2,85 & 35 \\
\hline & & & & & 123 & & & & & 124 & & & & & 120 \\
\hline
\end{tabular}

n- Número de amostras reagentes.

t- Número total de amostras analisadas. 
Tabela 2 - Títulos obtidos em duas coletas (agosto ${ }^{\mathrm{a}}$ e novembro ${ }^{\mathrm{b}}$ de 1999), obtidos por hemaglutinação indireta (HAI), hemaglutinação indireta 2-mercaptoetanol (HAI 2-ME) e imunofluorescência indireta (IFI) para detecção de anticorpos anti-Toxoplasma gondii em ovelhas e em seus respectivos cordeiros

\begin{tabular}{|c|c|c|c|c|c|c|c|c|c|}
\hline \multirow[b]{3}{*}{$\mathrm{N}^{\circ}$} & \multicolumn{3}{|c|}{ ovelhas } & \multicolumn{6}{|c|}{ cordeiros } \\
\hline & \multirow{2}{*}{$\frac{\text { HAI }}{\text { IgG }}$} & \multirow{2}{*}{$\frac{\text { HAI - 2ME }}{\text { IgM }}$} & \multirow{2}{*}{$\frac{\text { IFI }}{\text { IgG }}$} & \multicolumn{4}{|c|}{ HAI/HAI-2ME } & \multicolumn{2}{|c|}{ IFI } \\
\hline & & & & $\operatorname{IgG}^{\mathrm{a}}$ & $\operatorname{IgM}^{\mathrm{a}}$ & $\operatorname{IgG}^{\mathrm{b}}$ & $\operatorname{IgM}^{\mathrm{b}}$ & $\operatorname{IgG}^{\mathrm{a}}$ & $\operatorname{IgG}^{\mathrm{b}}$ \\
\hline 1 & 1024 & + & 2560 & 2048 & + & 8192 & - & 5120 & 10240 \\
\hline 2 & - & - & 320 & - & - & - & - & 20 & - \\
\hline 3 & 256 & - & - & - & - & - & - & - & - \\
\hline 4 & 128 & - & - & - & - & - & - & - & - \\
\hline 5 & 256 & + & 320 & 32768 & - & 131072 & - & 2560 & 5120 \\
\hline 6 & 512 & + & - & - & - & - & - & - & - \\
\hline 7 & 512 & - & 160 & - & - & - & - & 20 & - \\
\hline 8 & 128 & - & - & - & - & - & - & - & - \\
\hline 9 & - & - & 160 & - & - & 32 & - & 160 & 2560 \\
\hline 10 & - & - & 320 & - & - & - & - & 80 & 20 \\
\hline 11 & - & - & 320 & - & - & - & - & 160 & - \\
\hline 12 & - & - & 320 & - & + & - & - & 80 & - \\
\hline 13 & - & - & 320 & - & - & - & - & 160 & - \\
\hline 14 & - & - & 10240 & - & - & - & - & 160 & 80 \\
\hline 15 & 512 & - & - & - & - & - & - & 40 & - \\
\hline 16 & - & - & 160 & - & - & - & - & 160 & 80 \\
\hline 17 & 512 & - & 2560 & 32 & - & - & - & 320 & -40 \\
\hline 18 & - & - & 320 & & - & - & - & 160 & - \\
\hline 19 & 512 & - & - & & - & - & - & 80 & - \\
\hline 20 & - & - & 160 & & - & - & - & 160 & - \\
\hline 21 & - & - & 320 & & - & - & - & 160 & 80 \\
\hline
\end{tabular}

segunda coleta (4-2048-HAI)(4c-5120-IFI) nos dois testes. Os títulos dos demais cordeiros, que eram iguais ou superiores a 32, não alcançaram níveis mensuráveis na segunda coleta e esses resultados confirmaram-se no teste IFI.

Nas amostras analisadas nos dois rebanhos, houve quatro cordeiros $(3,3 \%)$ cujas mães apresentaram títulos de IgG, e os títulos desses cordeiros foram crescentes da primeira para segunda coleta. Destas quatro mães reagentes, três foram IgM positivas, caracterizando a fase aguda da doença. Segundo CAMARGO (1991), nos animais infectados, os títulos de anticorpos IgG são ascendentes ou permanentes e os anticorpos IgM são de curta duração,

Tabela 3 - Títulos referentes a duas coletas (agosto $^{\mathrm{a}}$ e novembro ${ }^{\mathrm{b}}$ de 2000), obtidos através de hemaglutinação indireta (HAI), hemaglutinação indireta 2-mercaptoetanol (HAI 2-ME) e imunofluorescência indireta (IFI) para detecção de anticorpos antiToxoplasma gondii em ovelhas e em seus respectivos cordeiros.

\begin{tabular}{|c|c|c|c|c|c|c|c|c|c|}
\hline \multirow[b]{3}{*}{$\mathrm{N}^{\circ}$} & \multicolumn{3}{|c|}{ ovelhas } & \multicolumn{6}{|c|}{ cordeiros } \\
\hline & \multirow{2}{*}{$\begin{array}{l}\mathrm{HAI} / \\
\mathrm{IgG}\end{array}$} & \multirow{2}{*}{$\frac{\text { HAI-2ME }}{\text { IgM }}$} & \multirow{2}{*}{$\begin{array}{l}\text { IFI } \\
\text { IgG }\end{array}$} & \multicolumn{4}{|c|}{ HAI/HAI-2ME } & \multicolumn{2}{|c|}{ IFI } \\
\hline & & & & $\operatorname{IgG}^{\mathrm{a}}$ & $\operatorname{IgM}^{\mathrm{a}}$ & $\operatorname{IgG}^{\mathrm{b}}$ & $\operatorname{IgM}^{\mathrm{b}}$ & $\operatorname{IgG}^{\mathrm{a}}$ & $\operatorname{IgG}^{\mathrm{b}}$ \\
\hline 1 & 512 & + & 320 & 128 & - & - & & 320 & 80 \\
\hline 2 & 512 & + & 320 & - & - & - & - & 160 & - \\
\hline 3 & - & - & 320 & - & - & - & - & 320 & 20 \\
\hline 4 & 8192 & + & 10240 & 512 & - & 2048 & - & 2560 & 5120 \\
\hline 5 & 512 & + & 320 & 32 & - & - & - & 320 & 80 \\
\hline 6 & 32 & - & 320 & - & - & - & - & 320 & 80 \\
\hline 7 & 512 & - & 320 & 1024 & - & - & - & 160 & 80 \\
\hline 8 & 512 & + & 320 & 32 & - & - & - & 320 & 80 \\
\hline 9 & 128 & - & 320 & - & - & - & - & 320 & 320 \\
\hline
\end{tabular}


pois sua meia vida é de cinco dias, o que evidenciaria a transmissão congênita ou a infecção muito recente dos animais analisados. Seria possível inferir, a partir desta informação, que, nos animais analisados no presente trabalho, ocorreria situação semelhante, ou seja, que a transmissão congênita teria ocorrido.

Os títulos desses quatro cordeiros foram, na maioria, iguais ou superiores a 2560 para IFI e a 2048 para HAI, na primeira coleta. Estes dados podem ser comparados ao trabalho de DUBEY et al. (1987a), pois, em estudo de toxoplasmose congênita em cordeiros, relataram que a presença de títulos maiores ou iguais a 4096, nos cordeiros com 3 a 4 meses, era indicativo de infecção congênita, porque os anticorpos adquiridos passivamente pelo colostro desaparecem ou decrescem para valores bem baixos três meses após o nascimento.

Comparando os dados encontrados no presente trabalho com outros (BLEWETT \& TREES, 1987; DUNCANSON et al, 2001), pode ser observado que os dados de prevalência aqui encontrados são menores que os apontados por autores de países do hemisfério norte, onde o sistema de criação é diferente. Assim, a carga de animais por unidade de campo no Sul do Brasil é menor, o que pode influenciar a possibilidade de infecção das ovelhas. Além disso, o genótipo do parasita e do hospedeiro, o período de infecção e também a duração da infecção antes da gestação são fatores importantes na epidemiologia desta parasitose.

\section{CONCLUSÕES}

Há que se considerar que: (1) os cordeiros analisados ainda estavam na fase de amamentação e provavelmente ainda não pastavam por ocasião da segunda coleta. Desta maneira, o perfil sorológico de alguns dos animais infectados sugere que estes mantiveram contato com o agente causal da toxoplasmose, recebido da mãe, embora não evidenciassem sinais clínicos; (2) os cordeiros, cujas mães eram IgM reagentes e apresentaram títulos de IgG que decresceram ou não ficaram evidenciados na segunda coleta, receberam anticorpos passivamente pelo colostro; e, por fim, (3) os filhos que tiveram seus títulos elevados da primeira para a segunda coleta, fazem crer que tenha ocorrido a transmissão congênita do $\mathbf{T}$. gondii.

\section{FONTES DE AQUISIÇÃO}

a- INSPETORIA VETERINÁRIA DE ROSÁRIO DO SUL. 2001. Dados fornecidos em 1ํ de Março de 2001. Rosário do Sul, RS, Brasil.

b- PREFEITURA MUNICIPAL DE ROSÁRIO DO SUL.
Cadastro da Secretaria Municipal da Fazenda. Dados fornecidos em 1ํ de março de 2001. Rosário do Sul, RS, Brasil.

c- Biolab- Mérieux S. A - Estrada do Mapuá,491-JacarepaguáRJ

d- Sigma-Aldrich Química Brasil Ltda.- R. Sabará 566- 5o andarCj. 53 São Paulo, Brasil

\section{REFERÊNCIAS}

BERTSCHINGER, B. Técnicas de imunofluorescência e análise interpretativa dos resultados. Porto Alegre: Edição do Autor, 1980. 115p.

BEVERLEY, J.K.A. et al. The pathology of the fetus ovine abortion due to toxoplasmosis. Vet Rec, v.88, p.174-178, 1971.

BLEWETT, D.A.; TREES, A.J. The epidemiology of ovine toxoplasmosis with especial respect to control. Brit Vet $\mathbf{J}$, v.143, p.128-135, 1987.

BLEWETT, D.A.; WATSON, W.A. The epidemiology of ovine toxoplasmosis. III. Observations on outbreaks of clinical toxoplasmosis in relation to possible mechanism of transmission. Brit Vet J, v.140, p.54-63, 1984.

BUXTON, D. Toxoplasmosis. In: MARTIN, W. B.; AITKEN, I.D. Diseases of sheep. 2.ed. Edinburgh: Blackwell Scientific, 1991. p.49-57.

CAMARGO, M.E. et al. Avidez de anticorpos IgG específicos como marcadores de infecção primária recente pelo Toxoplasma gondii. Rev Inst Med trop S Paulo, v.33, p.213-218, 1991.

CAMARGO, M.E. Toxoplasmose. In: FERREIRA, W.A.; ÁVILA S.L.M. Diagnóstico laboratorial das principais doenças infecciosas e auto-imunes. Rio de Janeiro: Guanabara-Koogan, 1996. p.165-174.

DA COSTA, A.J. Toxoplasmose em ruminantes domésticos. In: SEMINÁRIO BRASILEIRO DE PARASITOLOGIA VETERINÁRIA, 1980, Fortaleza, CE. Anais... Fortaleza: Colégio Brasileiro de Parasitologia Veterinária, 1980. 254p. p.128.

DUBEY, J.P. Toxoplasma, Neospora, Sarcocystis and other tissue cyst-forming of human and animals. In: KRIER, J.P. Parasitic Protozooa. 2.ed. San Diego: Academic, 1993. p.157-162.

DUBEY, J.P. Toxoplasmosis. J Am Vet Med Assoc, v.205, p.1593-1598, 1994.

DUBEY, J.P. et al. Serodiagnosis of postnatally and prenatally induced toxoplasmosis in sheep. Am J Vet Res, v.48, p.12391243, 1987a.

DUBEY, J.P. et al. Placental transfer of specific antibodies during ovine congenital toxoplasmosis. Am J Vet Res, v.48, p.474-476, 1987b.

DUBEY, J.P.; KIRKBRIDE, C.A. Economic and public health considerations of congenital toxoplasmosis in lambs. J Am Vet Med Assoc, v.195, p.1715-1716, 1989.

DUBEY, J.P.; KIRKBRIDE, C.A. Toxoplasmosis and other causes of abortion in sheep from northcentral United States. J Am Vet Med Assoc, v.196, p.287-290, 1990. 
DUNCANSON, P. et al. High levels of congenital transmission of Toxoplasma gondii in a commercial sheep flock. Int $\mathbf{J}$ Parasitol, v.31, p.1699-1703, 2001

FREYRE, A. et al. The incidence and economic significance of ovine toxoplasmosis in Uruguay. Vet Parasit, v.73,p.13-15, 1997.

FREYRE, A.; FALCON, J. Perfil de la toxoplasmosis y su transmisión al hombre en algunos países de América Latina. Rev Vet Uruguay, v.25, p.5-13, 1990.

KAWAZOE, U. Toxoplasma gondii. In: NEVES, D.P. Parasitologia humana. 11.ed. S. Paulo: Atheneu, 2005. p.163-172.
MARTIN, W. B. Epidemiological problems associated with some diseases of sheep. In: PROCEEDINGS OF THE SOCIETY OF VETERINARY EPIDEMIOLOGY AND PREVENTIVE VETERINARY MEDICINE, 1984, Edinburgh. Anais... Edinburgh: Society of Veterinary Epidemiology and Preventive Veterinary Medicine, 1984. 384p. p.1-5.

SPOSITO FILHA E. et al. Toxoplasma gondii em ovinos: isolamento do parasita a partir de diafragmas de animais procedentes do Estado do Rio Grande do Sul e abatidos em matadouros de São Paulo para consumo humano. Rev Bras Parasit Vet, v.1-2, p.117-119, 1992.

URQUHART, G.M. et al. Parasitologia veterinária. 2.ed. Rio de Janeiro: Guanabara Koogan, 1998. 292p. 